\title{
Absorption and retention characteristics of selenium in dorsal root ganglion neurons
}

\author{
Mamoru Haratake,* Kentaroh Koga, Mika Inoue, Takeshi Fuchigami \\ and Morio Nakayama*
}

Graduate School of Biomedical Sciences, Nagasaki University, 1-14 Bunkyo-machi, Nagasaki 852-8521, Japan. E-mail: haratake@nagasaki-u.ac.jp (M. Haratake); morio@nagasaki-u.ac.jp (M.Nakayama)

Selenium concentration in the brain tissue is far less variable than those in peripherals, such as the liver and kidney, in rodents, when fed a selenium-deficient diet. This fact implies the importance of this element for maintaining the integrity of brain functions and the distinctive selenium metabolism and/or the regulatory mechanism in the brain. To obtain basic information concerning the homeostatically maintained selenium store in the brain, we investigated absorption and retention characteristics of selenium from selenious acid (SA) and seleno-L-methionine (SeMet) into rat dorsal root ganglion (DRG) neurons, in comparison to isolated rat hepatocytes and renal cells in vitro. When DRG neurons were cultured in an SA-free medium subsequent to an SA-supplemented one for $24 \mathrm{~h}$, the DRG neurons maintained a higher selenium concentration than that before SA supplementation over a period of $96 \mathrm{~h}$ after removal of SA from the culture medium. The cellular glutathione peroxidase activity of the cells increased for $72 \mathrm{~h}$ after removal of SA from the culture medium. A similar retention characteristic of selenium was also observed for DRG neurons treated with SeMet-supplemented culture medium. Consequently, selenium from source 
compounds, in part, was thought to be retained in DRG neurons and then be utilized for the synthesis of selenium-containing proteins, which implied the presence of a neuron-specific selenium retention mechanism.

\section{Introduction}

Selenium is a metalloid element that belongs to Group 16 of the periodic table that shares similar chemical properties especially with sulfur and, to a lesser extent, with tellurium. This element is an essential micronutrient for humans and other higher animal species. Nutritional selenium is thought to be obtained from a variety of selenium compounds in the diet. $\quad$ Selenocysteine (SeCys), the 21st naturally occurring amino acid encoded by the UGA codon, is the form of selenium present in enzymes and proteins in mammals. Currently, 25 SeCys-containing proteins (selenoproteins) are identified in humans on the basis of their selenoproteome analysis, ${ }^{2}$ and their physiological roles and functions are being investigated..$^{3-6}$ Selenoproteins are ubiquitously expressed in all organs and tissues. The best-understood selenoproteins are the glutathione peroxidases family (GPx-1, GPx-2, GPx-3, GPx-4 and GPx-6) that can catalyze the reduction of certain peroxide species $(\mathrm{R}-\mathrm{OOH})$ to the alcohols (R-OH) at their active center SeCys residue. ${ }^{6}$ Particularly, phospholipid hydroperoxide GPx (GPx-4) is the only antioxidative enzyme that can directly reduce phospholipid hydroperoxides generated in biological membranes, which plays a critical role in the developmental process and biological activity. ${ }^{7-9}$

All mammals utilize oxygen as a fuel during respiration and in doing so generate a range of oxygen-derived radicals that impair many cellular processes. To deal with reactive oxygen species (ROS) such as superoxide anion and hydrogen peroxide, mammals have a 
range of antioxidant enzymes to remove these harmful by-products. The first step in the cascade is the transformation of the superoxide radical by superoxide dismutase resulting in production of hydrogen peroxide. GPxs then eliminate the hydrogen peroxide with catalase and peroxiredoxins..$^{10-14}$ The human brain, which claims $\sim 2 \%$ of total body mass, is responsible for $\sim 20 \%$ of total body oxygen consumption. ${ }^{15-17}$ In consequence of the high oxygen demand, the brain tissue inevitably induces the generation of large amounts of ROS, which are thought to be associated with the onset and/or progression of neurodegenerative diseases, such as Alzheimer's disease ${ }^{18-20}$ Parkinson's disease ${ }^{21-23}$ and epilepsy ${ }^{24,25}$, due to the ROS-mediated injury to certain brain regions from the early stages of the illnesses. Several papers have pointed out that decreases in GPx activity in the brain are associated with neurodegenerative diseases. ${ }^{26-28}$ In particular, the role of GPX-4 appears more important than other antioxidant enzymes due to the high lipid content in the brain. However, scant information on the absorption and subsequent metabolism of selenium source compounds in the brain has been obtained.

In our previous animal experiments, we observed that the selenium concentration in the brain is far less variable than those in peripheral tissues and organs in mice; When 3-week old male mice were fed a selenium-deficient diet $\left(0.004 \mu \mathrm{gSe} \mathrm{g}^{-1}\right)$ for 8 weeks, the selenium concentrations in the blood and the liver fell substantially down to 2.5 and $6.7 \%$, respectively, of those fed selenium-adequate diet $\left(0.250 \mu \mathrm{gSe} \mathrm{g}^{-1}\right){ }^{29} \quad$ However, the selenium concentration in the brain in the selenium-deficient mice decreased only to $47.8 \%$ of that in the selenium-adequate mice. Similar results were also reported in several papers. ${ }^{30}$ In addition, when selenious acid was administered orally to the selenium-deficient mice at a dose of 5 $\mu \mathrm{gSe} \mathrm{kg}^{-1}$ day $^{-1}$ for 7 days, the selenium concentrations in the blood and the liver significantly 
increased, respectively, to 370 and $251 \%$ of those in the selenium-deficient state. On the other hand, the selenium concentration in the brain did not change at all (102\%). Thus, the recovery of the selenium concentration in the brain was slow in comparison to those in the peripheral organs and tissues. ${ }^{31-33}$ These facts implied the importance of this element for maintaining the integrity of brain function, and the distinctive selenium metabolism in the brain. These observations also raised a question of whether such homeostatically maintained selenium store in the brain results from neurons-specific metabolism, the regulatory mechanism of the blood-brain barrier or both of them..$^{34,35}$ Although selenoprotein P (SelP) in the blood plasma is thought to play a key role in the systemic delivery of selenium, ${ }^{36}$ the regulatory mechanism of selenium in the brain tissue is not yet elucidated.

To obtain basic information concerning the homeostatically maintained selenium store in the brain, we conducted a cellular study using dorsal root ganglion (DRG) neurons. The antioxidant activity in neurons is likely to be more important than in the other cells in the brain, because $\sim 60-80 \%$ of the energy in the brain generated by respiration is used to support ongoing neuronal signaling. ${ }^{37}$ In this paper, we investigated absorption characteristics of selenium from inorganic and organic selenium source compounds into DRG neurons in comparison to isolated hepatocytes and renal cells. In addition, the bioavailability and retention behavior of selenium that is absorbed into DRG neurons were further examined.

\section{Experimental}

\section{Materials}

Selenium compounds, selenious acid (SA) and seleno-L-methionine (SeMet) were purchased 
from Kanto Chemical Co., Inc. (Tokyo, Japan) and Nacalai Tesque, Inc. (Kyoto, Japan), respectively. Dulbecco's modified Eagles medium (DMEM) was obtained from Invitrogen Corp. (Carlsbad, CA). Collagenase (type 1, 250-300 units $\mathrm{mg}^{-1}$ ), fetal bovine serum (FBS), nicotinamide adenine dinucleotide phosphate in the reduced form (NADPH) and glutathione reductase (GR) were from Wako Pure Chemical Ind., Ltd. (Osaka, Japan). Reduced glutathione (GSH) was from Tokyo Kasei Industry Co., Ltd. (Tokyo, Japan). Hydrogen peroxide used for the substrate to determine glutathione peroxidase activity and trypsin $\left(1,000-2,000\right.$ units $\mathrm{mg}^{-1}$, salt free) were from Nacalai Tesque, Inc. Water, used for the cell culture and enzyme activity measurements, was generated by a Milli-Q Biocel system (Millipore Corp., Billerica, MA).

\section{Isolation and culture of DRG neurons}

Dorsal root ganglia (DRG, Fig. S1, ESI $\dagger$ ) were dissected from male Wistar rats weighing 45-50 g under ether anaesthesia. The spinal column was excised rapidly, hemisected and placed in cold Hank's solution in an ice bath. Under microscopy, cervical, thoracic and lumbar ganglia ( 40 DRGs per rat) were then dissected out from the spinal column and the spinal roots and peripheral nerve trunk cut carefully away. Dissected ganglia were enzymatically disaggregated at $37{ }^{\circ} \mathrm{C}$ in Hank's solution with $0.05 \%$ collagenase for $2 \mathrm{~h}$ and subsequently $0.05 \%$ trypsin plus $0.02 \%$ ethylenediaminetetraacetic acid (EDTA) for $1 \mathrm{~h}$. Polystyrene Petri dishes (90 $\mathrm{mm} \phi$, Nalge Nunc Int'l, Waltham, MA) were pretreated with poly-L-lysine [average molecular weight 300,000, Sigma Co., Ltd. (St. Louis, MO)]. After washing twice with warm 10\% FBS containing DMEM medium by gentle pipetting, cells were plated onto the Petri dishes at a density of $\sim 5 \times 10^{5}$ cells dish $^{-1}$. Unless otherwise 
stated, the cells were cultured in DMEM medium supplemented with $10 \%$ heat-inactivated fetal bovine serum (maintenance medium) under humidified $5 \% \mathrm{CO}_{2}-95 \%$ air (NU-4750D, NuAire, Inc. Plymouth, MN). The dissociated DRG cells adhered to the bottom of the dishes within 30 min after plating. Proliferation of non-neurons was suppressed by addition of $10 \mu \mathrm{M}$ arabinosylcytosine for 24 to $48 \mathrm{~h}$ soon after plating, and at later times as required. DRG neurons at $7-10 \mathrm{~d}$ after plating $(\sim 70-80 \%$ confluence $)$ were subjected to all experiments (Fig. S2, ESI $\dagger$ ). ${ }^{38}$ For the selenium absorption experiments, SA and SeMet were dissolved in DMEM at 1000-fold high concentrations of the indicated values and added to the maintenance medium. All experiments with live animals were performed in compliance with the guidelines of the Nagasaki University on Animal Care and Use, and the institutional committee has approved the experimental protocols.

\section{Preparation of cell lysate of DRG neurons}

After washing five times with Hank's solution at indicated times in the time course experiments shown in the Figs, DRG neurons were treated with $0.05 \%$ trypsin plus $0.02 \%$ EDTA for 20 min. Neurons detached from 6 Petri dishes were collected in a polypropylene tube and then washed three times with Hank's solution. After aspiration of the washing solution, a hypotonic $0.02 \mathrm{M}$ tris(hydroxymethyl)aminomethane (Tris)- $\mathrm{HCl}$ buffer ( $\mathrm{pH} 7.4$ ) was added to the tube for osmotic cell lysis. The neurons suspension was further sonicated in a bath sonicator for $10 \mathrm{~min}$ and left for another $5 \mathrm{~min}$. The samples were centrifuged at $2,000 \mathrm{~g}$ for $10 \mathrm{~min}$. The protein concentration in the resulting supernatant was determined by the Lowry method using bovine serum albumin as the standard material. The supernatant was subjected to the determinations of cellular glutathione peroxidase activity and selenium 
concentrations.

\section{Determination of cellular glutathione peroxidase activity}

The cytosolic fraction was combined with EDTA $(0.63 \mathrm{mM})$, sodium azide $(0.63 \mathrm{mM})$, glutathione reductase solution (0.63 unit), reduced glutathione solution $(0.63 \mathrm{mM})$, and NADPH solution $(2.34 \mathrm{mM})$ in $0.05 \mathrm{M}$ phosphate buffer $(\mathrm{pH} 7.4)$. The reaction was initiated by the addition of hydrogen peroxide solution $(3.14 \mathrm{mM})$. Absorbance at $340 \mathrm{~nm}$ due to the NADPH was recorded every $10 \mathrm{~s}$ just after mixing by inversion. The GPx-like activity was calculated using the following equation (1) as $\mu$ moles NADPH oxidized per minute, where $\Delta A_{\mathrm{SAM}}$ is the decrease in absorbance at $340 \mathrm{~nm}$ of the sample solutions between 10 and $70 \mathrm{sec}$ after addition of the substrates, $\Delta A_{\mathrm{BLK}}$ is the decrease in absorbance at $340 \mathrm{~nm}$ per minute of the solutions using saline instead of the sample solutions, 20.6 is the dilution factor, $\varepsilon_{\mathrm{mM}}$ is the extinction coefficient for $1 \mathrm{mM}$ NADPH solution $\left(6.22 \mathrm{mM}^{-1} \mathrm{~cm}^{-1}\right)$, and $\mathrm{c}$ is the protein content $(\mu \mathrm{g}) .^{39}$

$$
\text { cGPx activity }=\left(\Delta A_{\mathrm{SAM}}-\Delta A_{\mathrm{BLK}}\right) \times 20.6 / \varepsilon_{\mathrm{mM}} / \mathrm{c} \cdots \cdots(1)
$$

\section{Determination of selenium concentration}

The selenium concentrations in the specimens after the determination of cGPx activity were fluorometrically determined using 2,3-diaminonaphthalene (DAN) after acid digestion with a 1:4 mixture by volume of perchloric acid and nitric acid. ${ }^{40}$ DAN was obtained from Tokyo Chemical Industry Co., Ltd. (Tokyo, Japan). The perchloric acid and nitric acid used were the specially prepared reagents grade for metal analysis from Nacalai Tesque, Inc. 
Fluorescence intensity at $520 \mathrm{~nm}$ from the selenium-DAN complex formation was monitored by a FP-6600 (JASCO, Tokyo, Japan) using the excitation wavelength at $375 \mathrm{~nm}$. The selenium standard solution [1,000 ppm as selenium (IV) dioxide in $0.5 \mathrm{M}$ nitric acid] for the fluorometry was obtained from Kanto Chemical Co., Inc. The selenium concentrations were given by dividing the selenium contents by the volume and the protein content of the cell lysates used for the acid digestion.

\section{Sodium dodecyl sulfate-polyacrylamide gel electrophoresis}

After measurement of the protein concentration by the Lowry method, the samples were dissolved in a mixture of $1 \%$ SDS, $0.01 \mathrm{M}$ Tris- $\mathrm{HCl}(\mathrm{pH} 7.4)$ and $10 \%$ sucrose. The samples containing $40 \mu$ g-protein were electrophoresed on a $12.5 \%$ polyacrylamide disk gel e-PAGEL (ATTO Corp., Tokyo, Japan) with an electrophoresis buffer [0.1\% SDS, $0.025 \mathrm{M}$ Tris and $0.192 \mathrm{M}$ glycine] at $20 \mathrm{~mA}$ plate ${ }^{-1}$ for $1.5 \mathrm{~h}$ using a pageRun AE-6531M (ATTO Corp.). The molecular mass calibration was carried out using Precision Plus Protein Standards that contain ten bands of $10-250 \mathrm{kDa}$ (Bio-Rad Lab., CA, USA). The locations of the proteins in the gels were determined by Coomassie blue (CB, Wako Pure Chemical Ind., Ltd.) staining (0.1\% CB in $30 \%$ methanol-acetic acid mixed solution). For the determination of selenium distribution in the gels, the 6 gel lanes were divided into three fractions according to the standard molecular mass samples (fraction I: $>37 \mathrm{kDa}$, fraction II : 20-37 kDa, fraction III: $<20 \mathrm{kDa}$ ) and then separately subjected to the DAN assay subsequent to the acid digestion. Data were presented as the selenium contents of the respective fractions per gel lane.

\section{Statistical analysis}


All data were presented as the mean and standard error $(\mathrm{SE})(n \geq 4)$. Statistical analyses were performed using PRISM 4 (GraphPad Software, Inc., La Jolla, CA, USA). The multiple mean values were compared by a one- or two-way analysis of variance with a Bonferroni post-hoc test. Comparisons were considered statistically significant at $P<0.05$.

\section{Results and discussion}

Selenium is present in inorganic and organic forms in the environment in various oxidation states -2 to +6 . The four natural oxidation states are as follows: $(-2)$, hydrogen selenide $\left(\mathrm{H}_{2} \mathrm{Se}\right) ;(0)$, elemental selenium, selenodiglutathione; $(+4)$, selenium dioxide $\left(\mathrm{SeO}_{2}\right)$, selenious acid $\left(\mathrm{SA}, \mathrm{H}_{2} \mathrm{SeO}_{3}\right)$; and (+6), selenic acid $\left(\mathrm{H}_{2} \mathrm{SeO}_{4}\right)$. Higher organisms requiring the selenium element can utilize a variety of inorganic and organic selenium compounds as selenium sources. ${ }^{1,41}$ In general, inorganic selenium compounds (e.g., SA) are superior to organic ones in the bioavailability of selenium, ${ }^{31,42}$ while organic bound selenium (e.g., SeMet) is less toxic than inorganic forms..$^{32,41}$ To test the selenium absorbability in DRG neurons, we used inorganic SA and organic SeMet as representative selenium sources for the absorption experiments. We also used dorsal root ganglion (DRG) neurons for the study of selenium absorption and retention behavior in neurons. DRG neurons have the same biological features as the brain neurons and are easily available from adult rodents.

First, DRG neurons were incubated in $1 \mu \mathrm{M}$ SA-supplemented culture medium, and the selenium concentration in the cells was followed (Fig. 1A). Selenium concentration in the cells was almost constant until $1 \mathrm{~h}$ after incubation and then gradually increased: 18 pgSe $\mu \mathrm{g}^{-1}$-protein after $6 \mathrm{~h}$ incubation and $90 \mathrm{pgSe} \mu \mathrm{g}^{-1}$-protein after $24 \mathrm{~h}$ incubation. No remarkable morphological changes and/or detachment from the Petri dishes of DRG neurons 
were observed during the exposure to $1 \mu \mathrm{M}$ SA and SeMet-supplemented culture media. The time-course of the selenium concentration in DRG neurons was compared to that is isolated rat hepatocytes treated under the same experimental conditions (Fig. 1A). The selenium concentration in the hepatocytes increased faster than that in the DRG neurons: 28 pgSe $\mu \mathrm{g}^{-1}$-protein just after $10 \mathrm{~min}$ incubation and $40 \mathrm{pgSe} \mu \mathrm{g}^{-1}$-protein after $1 \mathrm{~h}$ incubation. Such a selenium concentration change in the isolated rat hepatocytes was consistent with the previously reported data. ${ }^{33}$ A similar time-course trend was also observed for isolated rat kidney cells. SA absorption and/or the subsequent metabolism of DRG neurons appear different from those of peripheral cells. The observed difference in the selenium concentration change between DRG neurons and peripheral cells in vitro may be reflected in the organ absorption characteristics of selenium in vivo as shown in Fig. S2 (ESI $\dagger$ ). Second, the selenium absorption experiments were carried out using SeMet instead of SA (Fig. 1B). Selenium from SeMet was also absorbed into DRG neurons. It was found that selenium from SA and SeMet is absorbed into DRG neurons, as in the peripheral cells. However, selenium concentration in DRG neurons after $24 \mathrm{~h}$ incubation with SeMet (20 pgSe $\mu \mathrm{g}^{-1}$-protein) was lower than that with $\mathrm{SA}$ (90 $\mathrm{pgSe} \mu \mathrm{g}^{-1}$-protein). This trend was also observed for the isolated rat hepatocytes. Thus, the selenium absorption behavior appears to depend on the absorption and the intracellular metabolism manner of the selenium compounds.

Selenium compounds absorbed into living cells are utilized for the synthesis of selenocysteine subsequent to enzymatic and/or non-enzymatic reduction to reactive metabolites in low oxidation states. Subsequently, SeCys is inserted into polypeptide chains by a specific mechanism other than that for twenty kinds of naturally occurring amino acids. ${ }^{4,6}$ 
From the results shown in Fig. 1, it was confirmed that DRG neurons can absorb selenium from SA and SeMet supplemented in the culture media. To examine how selenium from these compounds can be absorbed and available for utilization for selenoprotein synthesis (selenium bioavailability), the enzyme activity of cGPx, the most abundant intracellular selenoprotein, was sequentially monitored. SA supplementation gave rise to similar increases in cGPx activity in a concentration range of 0.1 to $1 \mu \mathrm{M}$ (Fig. 2A). SeMet supplementation also provided an increase in cGPx activity at $1 \mu \mathrm{M}$ but was less effective at $0.5 \mu \mathrm{M}$ (Fig. 2B). Thus, selenium from both selenium compounds in the culture media was thought to be utilized for the synthesis of cGPx. The cGPx activity in terms of the area under the incubation time ( 0 to $48 \mathrm{~h}$ after addition SA or SeMet)-the cGPx activity curve (AUC, a measure of selenium bioavailability) in Fig. 2 was semi-quantitatively compared, (Table 1). The value of $\mathrm{AUC}_{0-48 \mathrm{~h}}$ for $0.1 \mu \mathrm{M} \mathrm{SA}\left(4.82 \mathrm{~h} \cdot \mathrm{U} \mathrm{L}^{-1} \mu \mathrm{g}^{-1}\right.$-protein) was comparable to those for $0.5\left(5.01 \mathrm{~h} \cdot \mathrm{U} \mathrm{L}^{-1} \mu \mathrm{g}^{-1}\right.$-protein) and $1 \mu \mathrm{M} \mathrm{SA}\left(4.93 \mathrm{~h} \cdot \mathrm{U} \mathrm{L}^{-1} \mu \mathrm{g}^{-1}\right.$-protein), while the value for $0.5 \mu \mathrm{M}$ SeMet $\left(2.80 \mathrm{~h} \cdot \mathrm{U} \mathrm{L}^{-1} \mu \mathrm{g}^{-1}\right.$-protein) was significantly smaller than that for 1 $\mu \mathrm{M}$ SeMet (5.40 $\mathrm{h} \cdot \mathrm{U} \mathrm{L}^{-1} \mu \mathrm{g}^{-1}$-protein). Consequently, the bioavailability of SA was superior to that of SeMet in DRG neurons, similar to the manner of these compounds in peripheral cells.

As mentioned earlier, selenium concentration in the brain does not decrease substantially when fed with a selenium-deficient diet for a long period. If the supplementation of selenium compounds in the culture media is stopped, do DRG neurons export most of the selenium from SA and SeMet to the culture media? Is the increased selenium concentration in the cells back to the basal level before SA and SeMet supplementations, or is the some of the selenium retained in the cells? To examine the fate of selenium that was absorbed into 
the DRG neurons, the cells were first incubated in SA and SeMet-supplemented culture media (selenium concentrations, $0.1-1 \mu \mathrm{M}$ ) for $24 \mathrm{~h}$ and subsequently in SA and SeMet-free media for $48 \mathrm{~h}$, and the cGPx activity of the cells was monitored (Fig. 3). The cGPx activities of the DRG neurons treated with $1 \mu \mathrm{M}$ SA and SeMet increased after removal of these compounds from the culture media. In the case of SA, cGPx activities even at 0.1 and 0.5 $\mu \mathrm{M}$ were retained at higher levels in comparison to the basal level before the SA supplementation at time $-24 \mathrm{~h}$.

To examine the retention behavior of selenium from SA and SeMet in DRG neurons, the cells were cultured in the selenium compound-free medium subsequent to the selenium compound-supplemented one for $24 \mathrm{~h}$, and changes in the selenium concentration and cGPx activity of the cells were followed (Fig. 4). Significant increases in the selenium concentration were observed for DRG neurons treated with either compound for $24 \mathrm{~h}$ (at time $0 \mathrm{~h}$ ). After the removal of selenium compounds from the culture media, the selenium concentrations in the cell lysates of DRG neurons largely decreased within $24 \mathrm{~h}$ incubation in SA-free 10\% FBS-containing DMEM. Such a rapid export of selenium from the cells may involve alkyl selenium compounds (e.g., dimethyl selenide, trimethyl selenonium) which are the primary products of detoxification of selenium in living systems under conditions of excessive uptake of SA. However, DRG neurons treated with SA-supplemented culture medium maintained a significantly higher selenium concentration than that before SA supplementation (at time $-24 \mathrm{~h}$ ) over a period of $96 \mathrm{~h}$ after removal of SA from the culture medium (Fig. 4A). Thus, a part of the selenium from SA that was absorbed into the DRG neurons was retained without being completely exported. The cGPx activity in the SA-supplemented cells still increased gradually for $72 \mathrm{~h}$ after removal of SA from the culture 
medium. A similar retention characteristic of selenium was also observed for DRG neurons treated with SeMet-supplemented culture medium. The amount of selenium retained in DRG neurons from SA supplementation was different from that from SeMet supplementation, which probably depends on the intracellular metabolism manner and rate of these compounds. In addition, the cGPx activity also remained higher than the basal level after incubation in SeMet-free culture medium (Fig. 4B). These results demonstrate that selenium from SA and SeMet is retained, in part, in the cytosol of the DRG neurons and is utilized for the synthesis of cGPx, even after stopping the supplementation of selenium compounds in the culture media.

The essential medium DMEM used does not contain selenium compounds at all, but FBS does have a trace amount of selenium from selenoprotein $\mathrm{P}^{43,44}$ The actual selenium concentration in the FBS used in this study was $9 \mathrm{ngSe} \mathrm{mL}^{-1}$, when determined by the DAN method. Hence, SA and SeMet-free 10\% FBS-containing DMEM still contain selenium at a concentration of $\sim 0.9 \mathrm{ngSe} \mathrm{mL}^{-1}$. Selenium in the basal level before the SA supplementation is thought to be supplied from the selenium species in FBS. Thus, after the incubation with $1 \mu$ M SA-supplemented 10\% FBS-containing DMEM for $24 \mathrm{~h}$, the DRG neurons were incubated in both SA- and FBS-free DMEM for another $24 \mathrm{~h}$, and the selenium concentration and cGPx activity were determined. The selenium concentration in the DRG neurons treated with FBS-free DMEM was comparable to that with 10\% FBS-containing DMEM (Fig. 5A). Thus, a higher selenium concentration than the basal level at $-24 \mathrm{~h}$ was retained even though selenium supplementation was completely stopped in the FBS-free DMEM. However, the cGPx activity with the FBS-free DMEM became smaller than that with $10 \%$ FBS-containing DMEM and decreased nearly to the basal level during 24-h incubation (Fig. 5B). The 
decrease in cGPx activity may be explained by the suppression of cGPx synthesis in the DRG neurons due to the lack of a certain growth-promoting supplement from FBS, although an adequate amount of selenium is present in the cells. The protein content of the cells with the FBS-free DMEM (1.12 $\mathrm{mg} \mathrm{mL}^{-1}$-cell lysate) was in fact lower than that with $10 \%$ FBS-containing DMEM (2.03 $\mathrm{mg} \mathrm{mL}^{-1}$-cell lysate). The observed characteristic selenium retention of neurons may be associated with the homeostatically maintained selenium store in the brain tissue at whole-body level.

The data showing that cGPx activity increased after the removal of SA and SeMet from the culture media (Figs. 3 and 4) implied the existence of selenium species that is not yet incorporated into the selenoproteins in DRG neurons. From the viewpoint of selenium stoichiometry, it is quite unlikely that all of the selenium absorbed into the DRG neurons is incorporated into selenoproteins. ${ }^{10}$ Therefore, the selenium retained in DRG neurons after the removal of SA and SeMet was thought to bind to certain endogenous materials that allow to react with metabolites of SA and SeMet. So far, several cytosolic proteinous materials have been previously reported as candidates for the binding of reactive selenium metabolites. ${ }^{45,46}$ SelP has also been reported to be associated with the selenium delivery and storage in cells. ${ }^{47-49}$

When the cell lysates of the selenium-retaining DRG neurons treated with SA was ultrafiltered through a membrane with a molecular mass cutoff of $5 \mathrm{kDa}$, no selenium was detected in the filtrate. In most cases, thiol-containing peptides and proteins are associated with selenium metabolism and/or interactions of resulting metabolic species..$^{50,51}$ Therefore, the cell lysates were subjected to separation by sodium dodecyl sulfate-polyacrylamide gel electrophoresis. The electrophoregram of the cell lysate of DRG neurons incubated in the 1 
$\mu \mathrm{M}$ SA-supplemented medium for $24 \mathrm{~h}$ and subsequently in the SA-free medium for another 24 h (Fig. 6C) was not markedly different from that before SA treatment (the basal level, Fig. 6A) and that incubated in the $1 \mu \mathrm{M}$ SA-supplemented medium for $24 \mathrm{~h}$ (Fig. 6B). The obtained gels were divided into three fractions according to the molecular mass standards (fraction I, > $37 \mathrm{kDa}$; II, 20-37 kDa; III: < $20 \mathrm{kDa}$ ), and the selenium content in each fraction was then determined by the DAN method subsequent to the acid digestion of the gels. When the DRG neurons were incubated in SA-free medium for $24 \mathrm{~h}$ subsequent to the SA-supplemented medium for $24 \mathrm{~h}$, approximately $70 \%$ of the selenium applied to the gels was found in fraction III, and the rest was in fractions I and II ( 10 to $20 \%$ for each) (Fig. 6C). Thus, selenium found in the gel fractions was likely to bind cytosolic proteinous species that allow interacting metabolic intermediates of SA. If SA metabolites in DRG neurons bind to certain cytosolic high molecular mass compounds through thiols of Cys residues, dithiothreitol (DTT) treatment of the cell lysate could result in changes in the selenium distribution in the gel fractions due to reductive cleavage of covalent attachments such as selenenylsulfide $(-\mathrm{S}-\mathrm{Se}-)$ and selenotrisulfide $(-\mathrm{S}-\mathrm{Se}-\mathrm{S}-)$. Actually, the DTT-treatment led to almost complete release of selenium from the three gel fractions. Consequently, the selenium retained in the DRG neurons seems to bind to free thiol-containing peptides and/or proteins with a molecular mass less than $20 \mathrm{kDa}$. Although a similar trend was observed for the cell lysates from the SeMet-treated DRG cells, a large portion of selenium was ultrafiltered through the membrane.

In summary, we investigated the selenium absorption and retention characteristics of DRG neurons. DRG neurons could absorb selenium from both inorganic SA and organic SeMet supplemented into the culture media. The absorption behavior of selenium from 
these compounds into DRG neurons was different from that into peripheral hepatic and renal cells. The bioavailability of selenium from the two compounds was further studied by determining the enzymatic activity of cGPx that is the most abundant selenoprotein in cells. It was found that DRG neurons could also utilize SA and SeMet as a selenium source, as peripheral hepatocytes and kidney cells do. Selenium from SA and SeMet, in part, was retained in DRG neurons over a long period ( $~ 96 \mathrm{~h})$ after the removal of these compounds from the culture media, which could possibly be associated with the characteristic retention of selenium in the brain. We are now addressing the identification of such selenium-bound substances for elucidation of the mechanism underlying the characteristic retention of selenium in DRG neurons. 


\section{References}

1 M. P. Rayman, Lancet, 2000, 356, 233-241.

2 G. V. Kryukov, S. Castellano, S. V. Novoselov, A. V. Lobanov, O. Zehtab, R. Guigó and V. N.

Gladyshev, Science, 2003, 300, 1439-1443.

3 O. Oster, G. Schmiedel and W. Prellwitz, Biol. Trace Elem. Res., 1988, 15, $23-45$.

4 T. C. Stadtman, Ann. Rev. Biochem., 1990, 59, 111-127.

5 B. A. Zachara, E. B. B. K. M. Śliwka, JKŹS. Skok and K. Ryć, Arch. Environ. Health, 2001, 56, 461-466.

6 L. V. Papp, J. Lu, A. Holmgren and K. K. Khanna, Antioxid. Redox Signaling, 2007, 9, 775-806.

7 H. Imai and Y. Nakagawa, Free Radic. Biol. Med., 2003, 34, 145-169.

8 H. Imai, F. Hirao, T. Sakamoto, K. Sekine, Y. Mizukura, M. Saito, T. Kitamoto, M. Hayasaka, K.

Hanaoka and Y. Nakagawa, Biochem. Biophys. Res. Commun., 2003, 305, 278-286.

9 L. J. Yant, Q. Ran, L. Rao, H. V. Remmen, T. Shibatani, J. G. Belter, L. Motta, A. Richardson and T.

A. Prolla, Free Radic. Biol. Med., 2003, 34, 496-502.

10 J. R. Prohaska and H. E. Ganther, J. Neurochem., 1976, 27, 1379-1387.

11 R. Brigelius-Flohé, Free Radic. Biol. Med., 1999, 27, 951-965.

12 Y. Zhang, Y. Zhou, U. Schweizer, N. E. Savaskan, D. Hua, J. Kipnis, D. L. Hatfield and V. N.

Gladyshev, J. Biol. Chem., 2008, 283, 2427-2438.

13 G. Trépanier, D. Furling, J. Puymirat and M. E. Mirault, Neuroscience, 1996, 75, 231-243.

14 H. Steinbrrnner and H. Sies, Biochim. Biophys. Acta, 2009, 1790, 1478-1485.

15 R. G. Shulman, D. L. Rothman, K. L. Behar and F. Hyder, Trends Neurosci., 2004, 27, 489-495.

16 M. D. Fox and M. E. Raichle, Nat. Rev. Neurosci., 2007, 8, 700-711.

17 K. Aoyama, M. Watabe and T. Nakaki, J. Pharmacol. Sci., 2008, 108, 227-238.

18 D. Wenstrup, W. D. Ehmann and W. R. Markesbery, Brain Res. 1990, 533, 125-131.

19 I. Ceballos-Picot, M. Merad-Boudia, A. Nicole, M. Thevenin, G. Hellier, S. Legrain and C. Berr,

Free Radic. Biol. Med., 1996, 20, 579-587.

20 F. P. Bellinger, Q. P. He, M. T. Bellinger, Y. Lin, A. V. Raman, L. R. White and M. J. Berry, J.

Alzheimers Dis., 2008, 15, 465-472.

21 S. J. Kish, C. Morito and O. Hornykiewicz, Neurosci. Lett., 1985, 58, 343-346.

22 P. Johannsen, G. Velander, J. Mai, E. B. Thorling and E. Dupont, J. Neurol. Neurosurg. Psychiatry, 1991, 54, 679-682.

23 J. H. T. Power and P. C. Blumbergs, Acta Neuropathol., 2009, 117, 63-73.

24 M. R. Ashrafi, R. Shabanian, A. Abbaskhanian, A. Nasirian, M. Ghofrani, M. Mohammadi, G.R.

Zamani, Z. Kayhanidoost, S. Ebrahimi and Z. Pourpak, Pediatr. Neurol., 2007, 36, 25-29. 
25 M. Naziroglu, Neurochem. Res., 2009, 34, 2181-2191.

26 J. Chen and M. J. Berry, J. Neurochem., 2003, 86, 1-12.

27 U. Schweizer, A. U. Bräuer, J. Köhrle, R. Nitsch, N. E. Savaskan, Brain Res. Rev., 2004, 45, $164-178$.

28 F. P. Bellinger, A. V. Raman, M. A. Reeves and M. J. Berry, Biochem. J., 2009, 422, 11-22.

29 M. Haratake, M. Ono and M. Nakayama, J. Health Sci., 2004, 50, 366-371.

30 A. Nakayama, K. E. Hill, L. M. Austin, A. K. Motley and R. F. Burk, J. Nutr., 2007, 137, 690-693.

31 H. Zeng, J. H. Botnen and L. K. Johnson, Biol. Trace Elem. Res., 2008, 123, 98-108.

32 X. Wu, K. Huang, C. Wei, F. Chen and C. Pan, J. Nutr. Biochem., 2010, 21, 153-161.

33 Y. C. Park and P. D. Whanger, Toxicology, 1995, 100, 151-162.

34 K. S. Kim, Nat. Rev. Microbiol., 2008, 6, 625-634.

35 N. J. Abbott, A. A. K. Patabendige, D. E. M. Dolman, S. R. Yusof and D. J. Begley, Neurobiol. Dis., $2010,37,13-25$.

36 R. F. Burk, K. E. Hill, G. E. Olson, E. J. Weeber, A. K. Motley, V. P. Winfrey and L. M. Austin, J. Neurosci., 2007, 27, 6207-6211.

37 G. Buzsáki, K. Kaila and M. Raichle, Neuron, 2007, 56, 771-783.

38 K. Sango, H. Yanagisawa and S. Takaku, Histochem. Cell Biol., 2007, 128, 35-43.

39 L. Flohé and W. A. Günzler, Methods Enzymol., 1984, 105, 114-120.

40 T. M. T. Sheehan and M. Gao, Clin. Chem. (Washington, D. C.), 1990, 36, 2124-2126.

41 D. G. Barceloux, Clin. Toxicol., 1999, 37, 145-172.

42 K. E. Hill, J. Zhou, W. J. McMahan, A. K. Motley and R. F. Burk, J. Nutr., 2004, 134, 157-161.

43 J. Yan and J. N. Barrett, J. Neurosci., 1998, 18, 8682-8691.

44 Y. Saito and K. Takahashi, Eur. J. Biochem., 2002, 269, 5746-5751.

45 G. M. Lacourciere, R. L. Levine and T. C. Stadman, Proc. Natl. Acad. Sci. U. S. A., 2002, 99, 9150-9153.

46 M. Suzuki, D. Y. Lee, N. Inyamah, T. C. Stadman and N. Tjandra, J. Biol. Chem., 2008, 283, 25936-25943.

47 U. Schweizer, F. Streckfub, P. Pelt, B. A. Carlson, D. L. Hatfield, J. Köhrle, and L. Schomburg, Biochem. J., 2005, 386, 221-226.

48 D. R. Richardson, Biochem. J., 2005, 386, e5-e7.

49 K. E. Hill, J. Zhou, L. M. Austin, A. K. Motley, A. J. L. Ham, G. E. Olson, J. F. Atkins, R. F.

Gesteland and R. F. Burk, J. Biol. Chem., 2007, 282, 10972-10980.

50 M. Haratake, K. Fujimoto, M. Ono and M. Nakayama, Biochim. Biophys. Acta, 2005, 1723, $215-220$.

51 M. Haratake, M. Hongoh, M. Ono and M. Nakayama, Inorg. Chem., 2009, 48, 7805-7811. 
Table 1 Comparison of bioavailability of SA and SeMet in DRG neurons

\begin{tabular}{|c|c|c|c|c|c|}
\hline \multirow[b]{3}{*}{ Duration of time / $\mathrm{h}$} & \multicolumn{5}{|c|}{$\mathrm{AUC}^{\mathrm{a}} / \mathrm{h} \cdot \mathrm{U} \mathrm{L}^{-1} \mu \mathrm{g}^{-1}$-protein } \\
\hline & \multicolumn{3}{|c|}{$\mathrm{SA} / \mu \mathrm{M}$} & \multicolumn{2}{|c|}{ SeMet / $\mu \mathrm{M}$} \\
\hline & 0.1 & 0.5 & 1 & 0.5 & 1 \\
\hline 0 to 24 & 1.72 & 1.95 & 1.58 & 0.85 & 1.81 \\
\hline 24 to 48 & 3.10 & 3.05 & 3.34 & 1.95 & 3.59 \\
\hline 0 to 48 & 4.82 & 5.01 & 4.93 & 2.80 & 5.40 \\
\hline \multicolumn{6}{|c|}{$\begin{array}{l}{ }^{\text {a }} \text { Values of AUC were areas under incubation time-cGPx activity curves in Fig. } 2 \text { that were } \\
\text { calculated by the trapezoid method. } P<0.05, \mathrm{AUC}_{0-48 \mathrm{~h}} \text { for } 0.5 \mu \mathrm{M} \text { SA versus } \mathrm{AUC}_{0-48 \mathrm{~h}} \\
\text { for } 0.5 \mu \mathrm{M} \text { SeMet; not significant, } \mathrm{AUC}_{0-48 \mathrm{~h}} \text { for } 1 \mu \mathrm{M} \text { SA versus } \mathrm{AUC}_{0-48 \mathrm{~h}} \text { for } 1 \mu \mathrm{M} \text { SeMet. }\end{array}$} \\
\hline
\end{tabular}



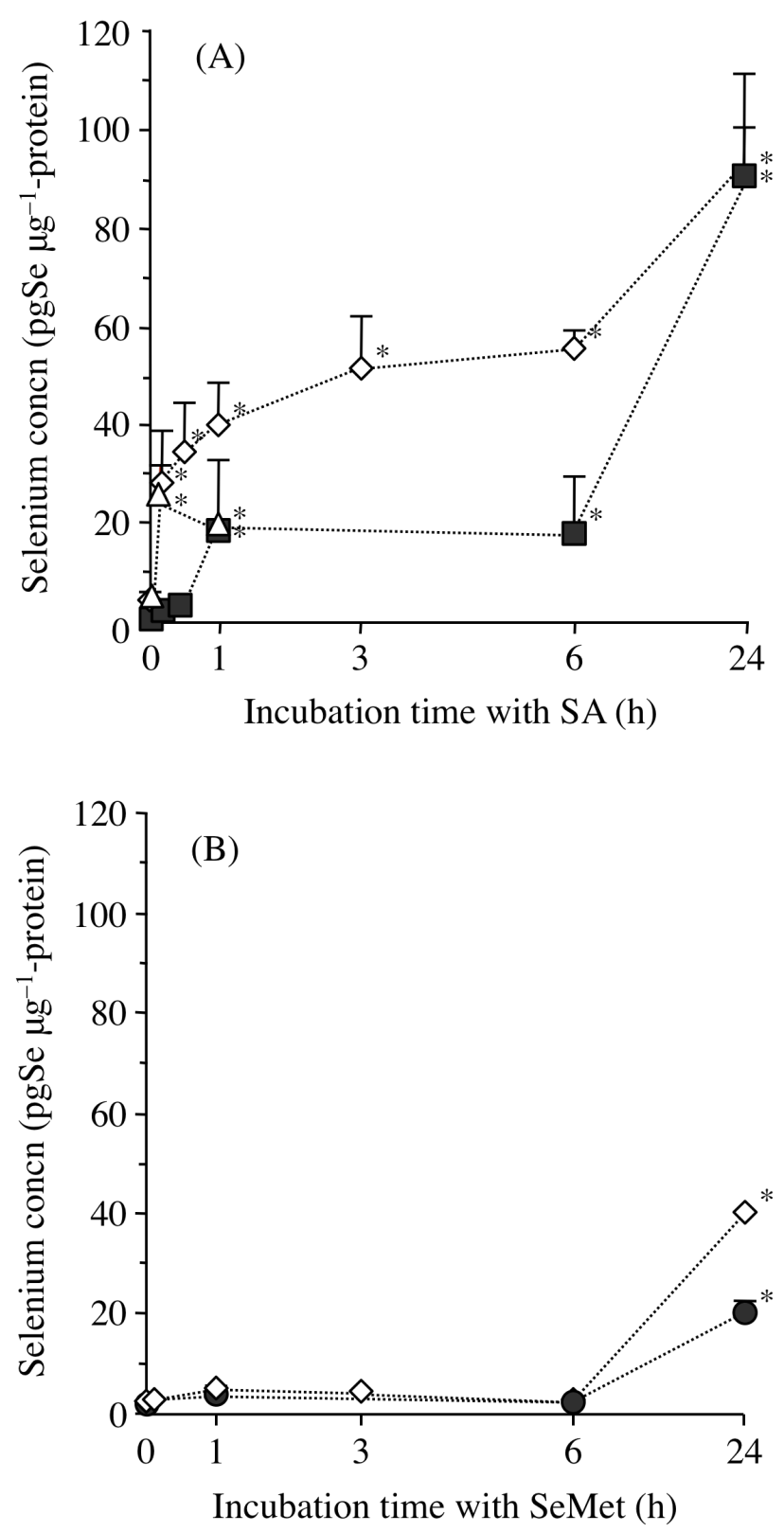

Fig. 1 Changes in selenium concentration of DRG neurons, hepatocytes and kidney cells incubated with SA (A) and SeMet (B). $\mathbf{\square}$ and $\boldsymbol{O}$, DRG neurons; $\diamond$, Hepatocytes; $\triangle$, Kidney cells. SA and SeMet concentrations in 10\% FBS-containing DMEM culture medium: $1 \mu \mathrm{M}$. Data express mean and SE $(n=4-5) . *$, Significantly different from the value at time 0 h with $P<0.05$. 

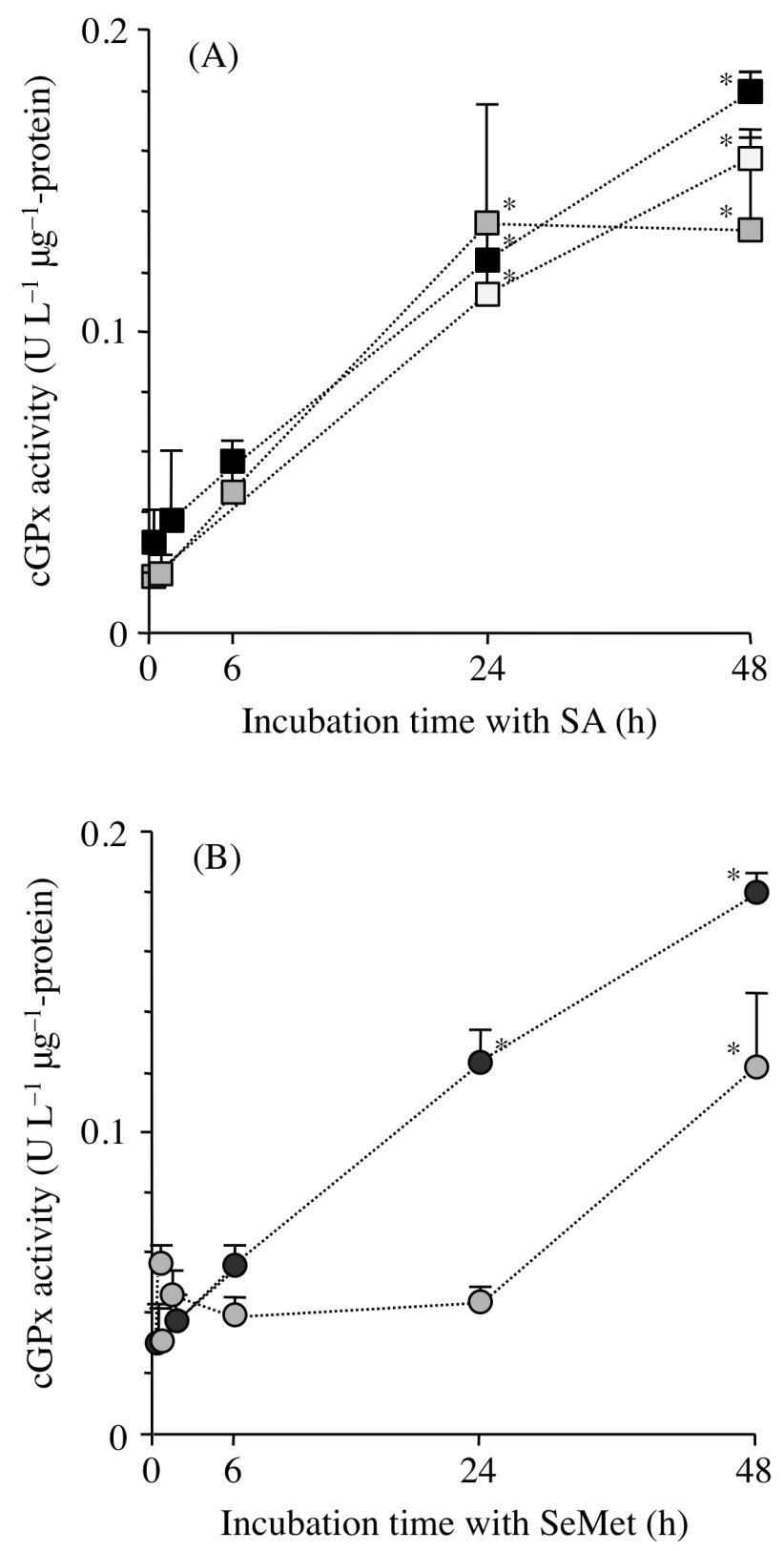

Fig. 2 Changes in cGPx activity of DRG neurons incubated with SA (A) and SeMet (B). SA and SeMet concentrations in 10\% FBS-containing DMEM culture medium. $\square, 0.1 \mu \mathrm{M} \mathrm{SA}$; $\square, 0.5 \mu \mathrm{M} \mathrm{SA} ; \mathbf{\square}, 1 \mu \mathrm{M}$ SA; $\bigcirc, 0.5 \mu \mathrm{M}$ SeMet;, $1 \mu \mathrm{M}$ SeMet. Data express mean and SE $(n=4-5) . *$, Significantly different from the value at time $0 \mathrm{~h}$ with $P<0.05$. 

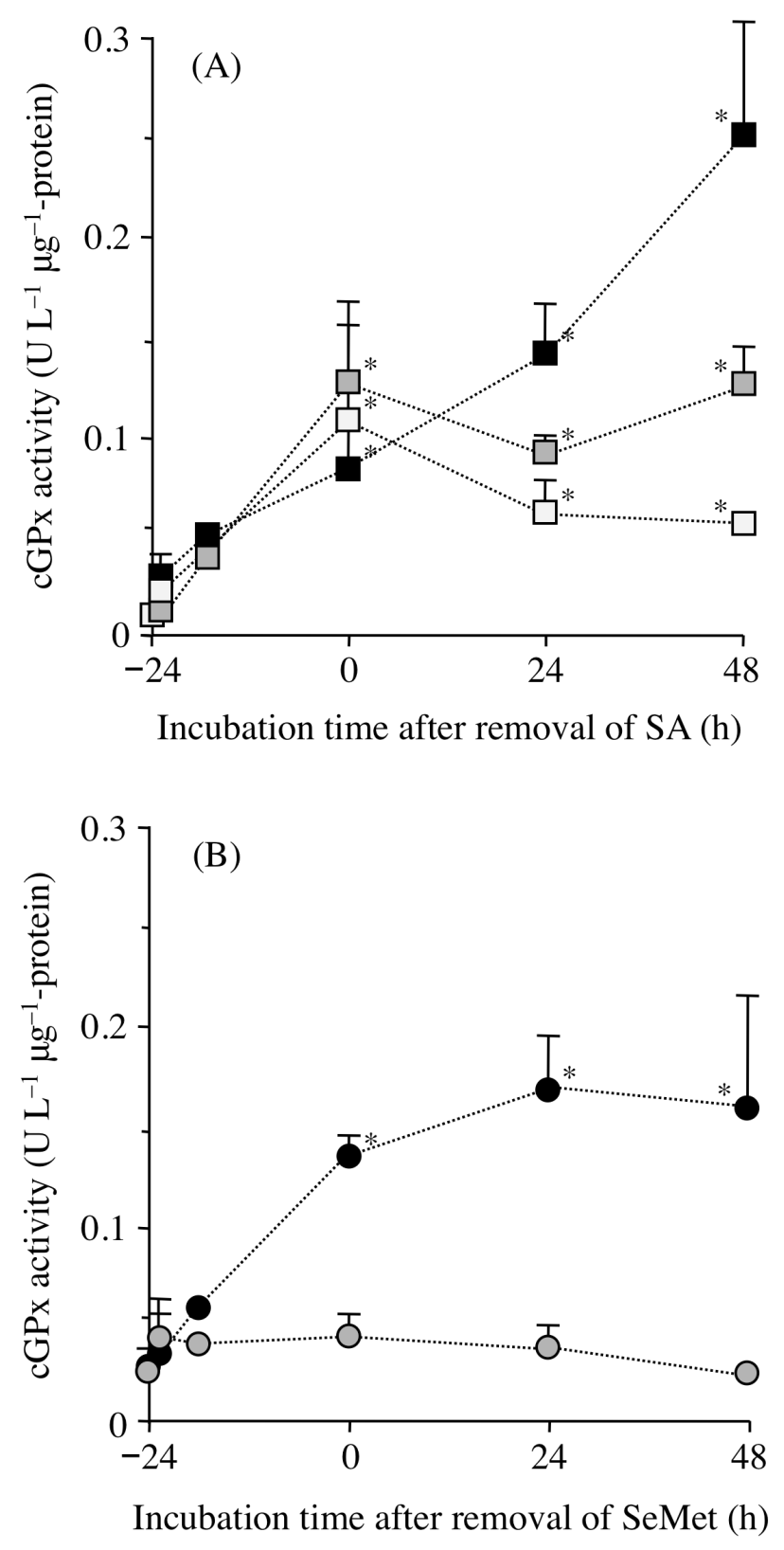

Fig. 3 Changes in cGPx activity of DRG neurons after removal of SA (A) and SeMet (B) from the culture media. Incubation conditions: time $-24-0 \mathrm{~h}$, SA and SeMet plus $10 \%$ FBS-containing DMEM culture medium; 0-96 h, SA and SeMet-free 10\% FBS-containing DMEM culture medium. Selenium compounds concentration: $\square, 0.1 \mu \mathrm{M}$ SA; $\square, 0.5 \mu \mathrm{M}$ $\mathrm{SA} ; \boldsymbol{\square}, 1 \mu \mathrm{M} \mathrm{SA} ; \mathrm{O}, 0.5 \mu \mathrm{M}$ SeMet;, $1 \mu \mathrm{M}$ SeMet. Data express mean and SE $(n=$ 4-5). *, Significantly different from the value at time $0 \mathrm{~h}$ with $P<0.05$. 


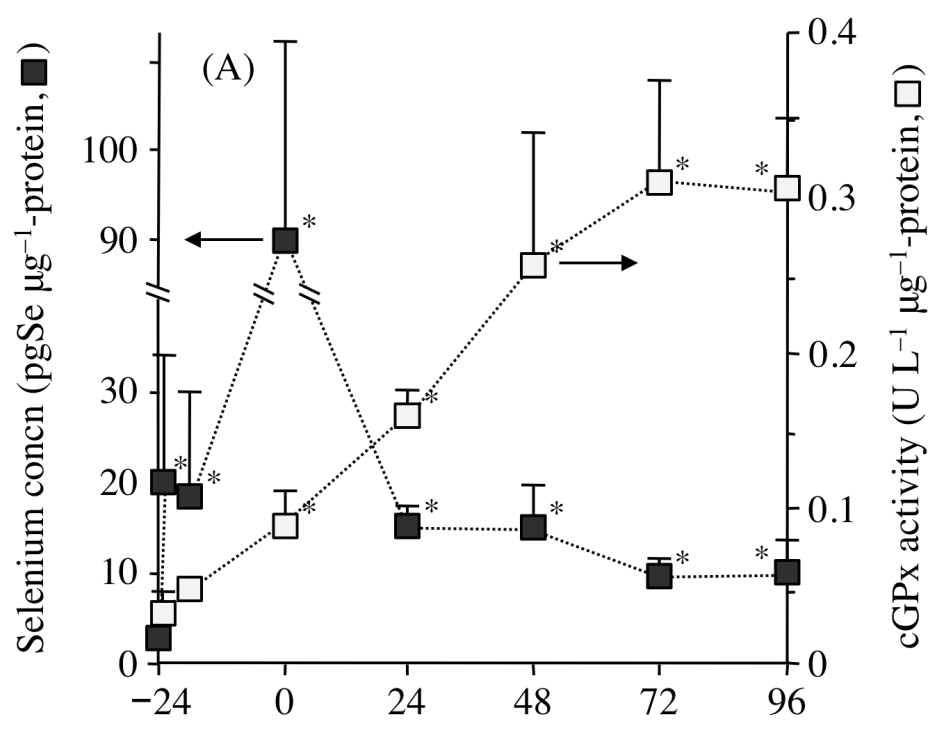

Incubation time after removal of SA (h)

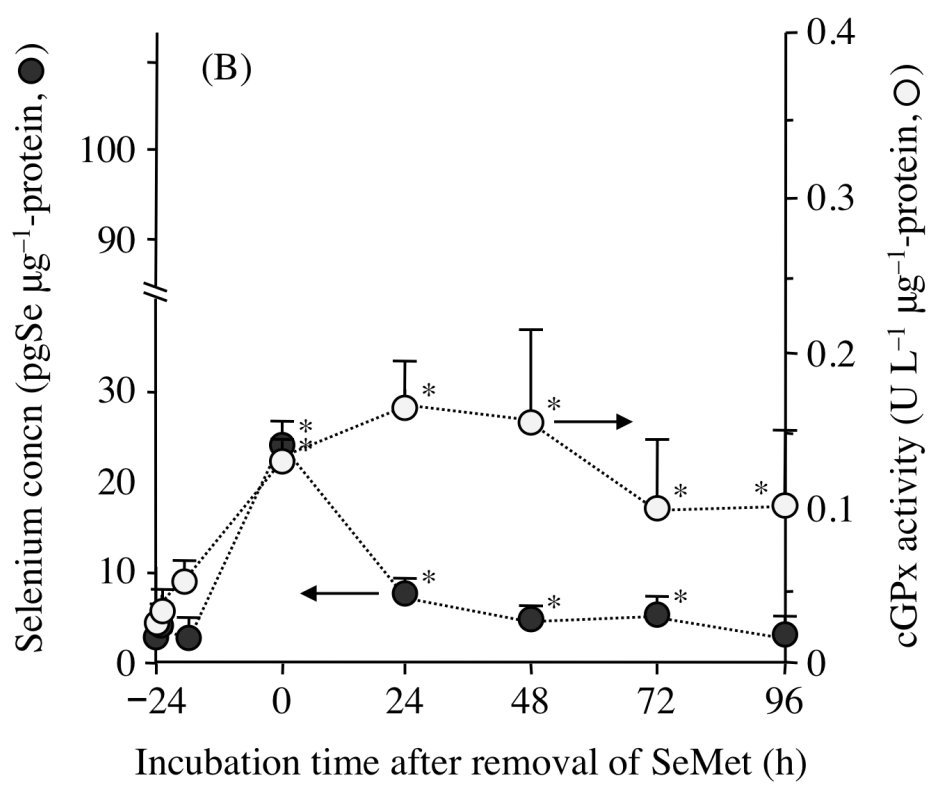

Fig. 4 Changes in selenium concentration and cGPx activity of DRG neurons after removal of SA (A) and SeMet (B) from the culture media. Incubation conditions: time $-24-0 \mathrm{~h}, 1 \mu \mathrm{M}$ SA and SeMet plus 10\% FBS-containing DMEM culture medium; 0-96 h, SA and SeMet-free 10\% FBS-containing DMEM culture medium. and $\bigcirc$, selenium concentration in the cell lysate; $\square$ and $O$, cGPx activity. Data express mean and SE $(n=4-5)$. *, Significantly different from the value at time -24 h with $P<0.05$. 


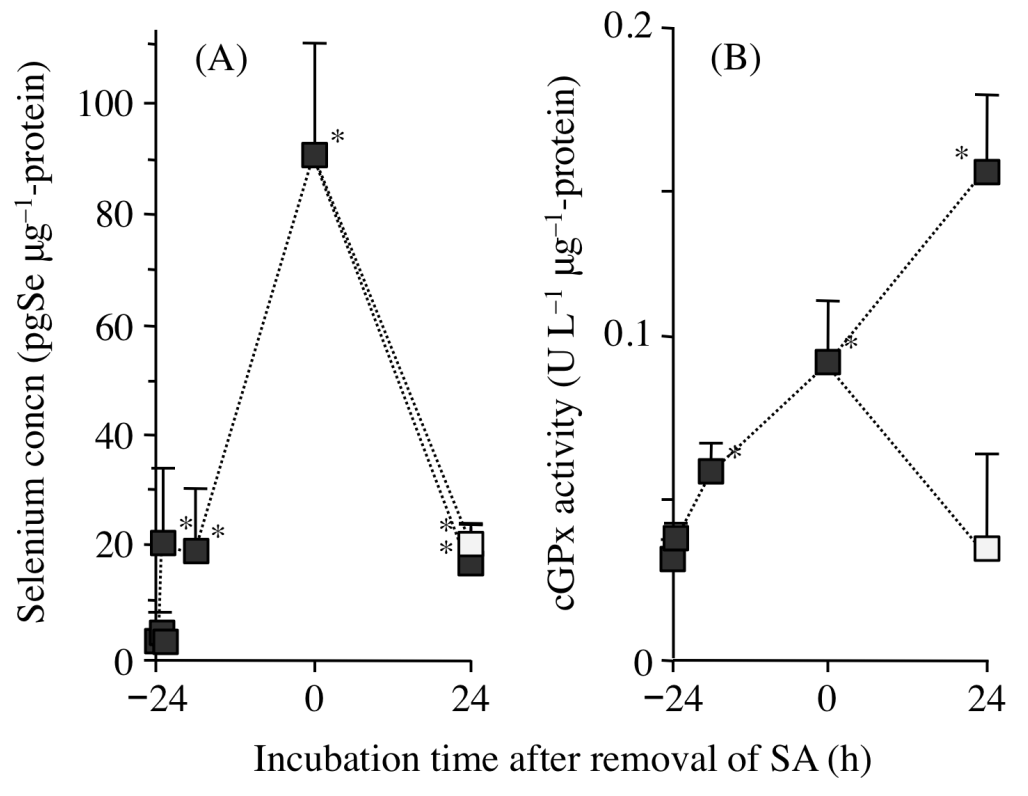

Fig. 5 Effects of fetal bovine serum (FBS) on selenium concentration (A) and cGPx activity (B) of DRG neurons after removal of SA from the culture media. $\mathbf{\square}$, treated with $10 \%$ FBS-containing DMEM culture medium during time 0 to $24 \mathrm{~h}$; $\square$, treated with FBS-free DMEM culture medium during time 0 to $24 \mathrm{~h}$. Data express mean and SE $(n=4-5)$. *, Significantly different from the value at time $-24 \mathrm{~h}$ with $P<0.05$. 

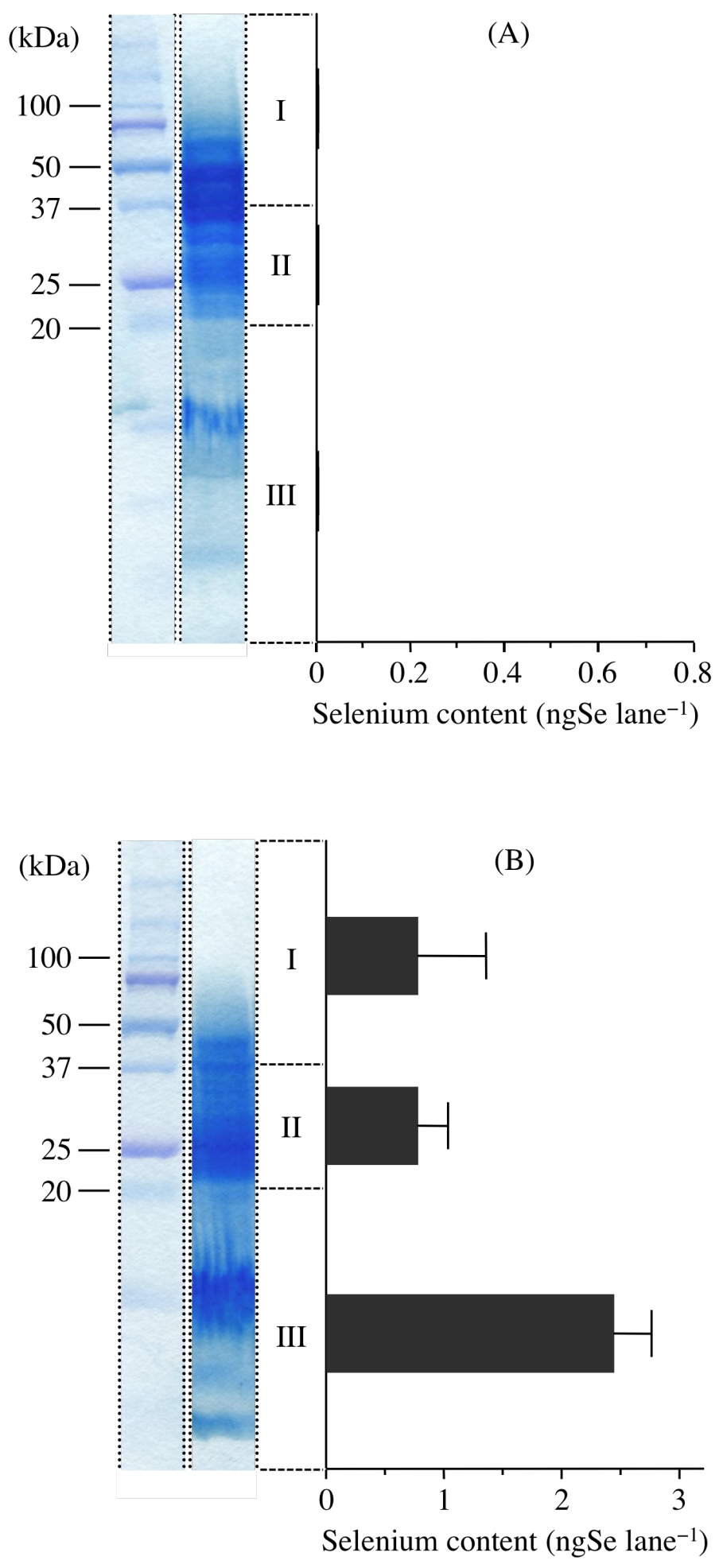


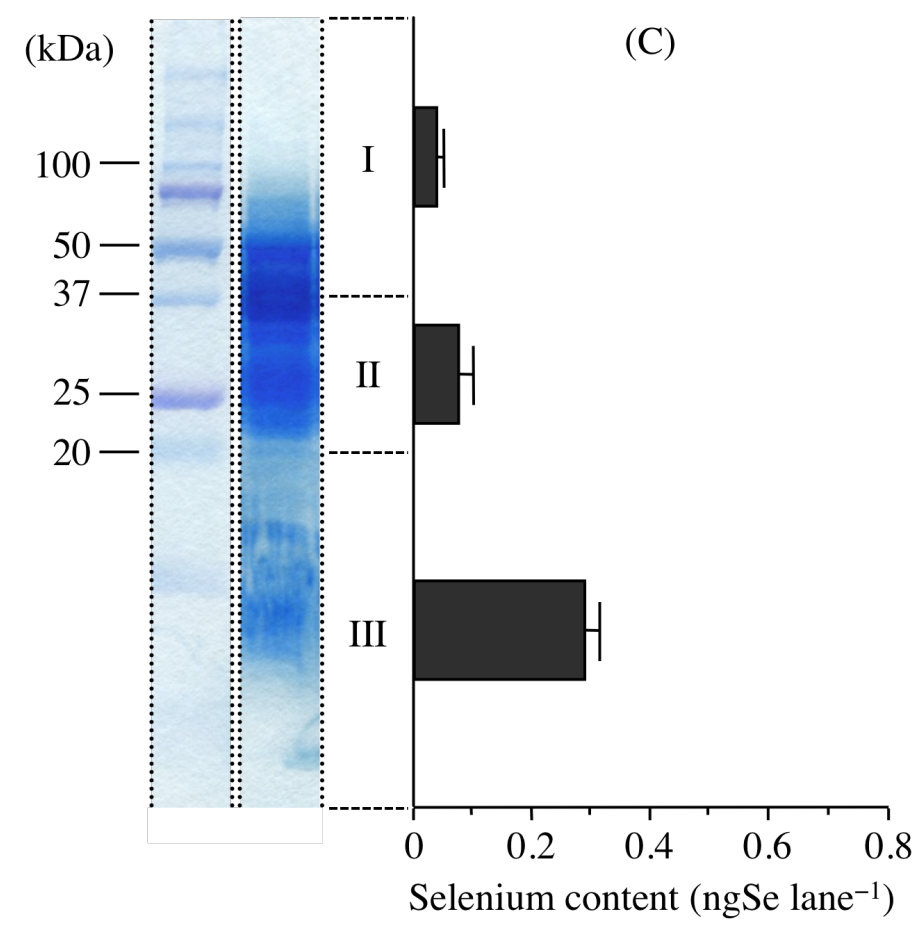

Fig. 6. Electrophoretic and selenium content analyses of the cytosolic components of DRG neurons. (A): before the treatment with $1 \mu \mathrm{M}$ SA-containing medium, $0.09 \mathrm{ngSe} \operatorname{lane}^{-1},(\mathrm{~B})$ : treated with $1 \mu \mathrm{M}$ SA-containing medium for $24 \mathrm{~h}, 3.58 \mathrm{ngSe} \operatorname{lane}^{-1}(\mathrm{C})$ : treated with SA-free medium for $24 \mathrm{~h}$ subsequent to $1 \mu \mathrm{M} \mathrm{SA}$-containing medium for $24 \mathrm{~h}, 0.59 \mathrm{ngSe}$ lane ${ }^{-1}$. Data express mean and SE $(n=4-5)$. 


\section{Graphical abstract for the contents entry page}

We investigated absorption and retention characteristics of selenium from selenious acid and selenomethionine into rat dorsal root ganglion (DRG) neurons in vitro. Selenium from source compounds, in part, was thought to be retained in DRG neurons and then be utilized for the synthesis of selenium-containing proteins.

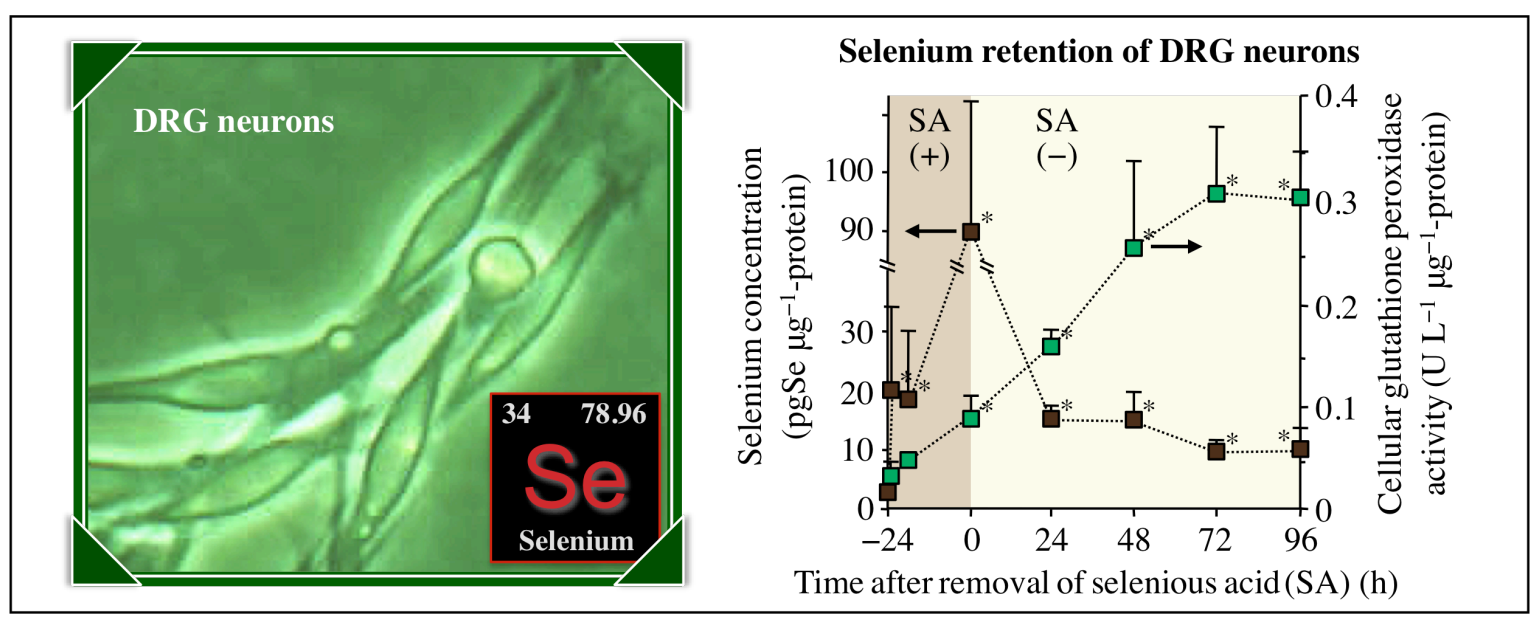

